\title{
“O CALÇADÃO É LEGAL": ESTUDO INTERPRETATIVISTA SOBRE OS SIGNIFICADOS ASSOCIADOS POR CONSUMIDORES DE BAIXA RENDA A UM POLO COMERCIAL DE RUA
}

\author{
"THE CALCADÃO IS NICE": AN INTERPRETATIVE STUDY ON THE \\ SYMBOLISM ASSOCIATED BY LOW-INCOME CONSUMERS TO A STREET \\ RETAIL SPACE
}

\author{
Vinicius Cunha \\ Pontifícia Universidade Católica do Rio de Janeiro \\ vlopes.cunha@gmail.com \\ Marcus Wilcox Hemais \\ Pontifícia Universidade Católica do Rio de Janeiro \\ marcus.hemais@iag.puc-rio.br
}

Submissão: $17 / 08 / 2018$

Aprovação: 13/12/2018

\begin{abstract}
RESUMO
Apesar de representarem um grande público comprador em polos varejistas, são poucos os estudos em marketing no Brasil que discutem a relação entre consumidores de baixa renda e tais locais, em especial os calçadões. O presente artigo, portanto, analisa os significados associados por consumidores de baixa renda a um polo comercial de rua, por meio de uma visão interpretativista. Para isso, foram realizadas entrevistas em profundidade com 17 consumidores de baixa renda no Calçadão de Campo Grande, no Rio de Janeiro. A análise dos dados discute como o calçadão em questão é tido como um espaço popular, especialmente por oferecer preços considerados baixos e devido ao sentimento de crowding com o seu ambiente. Reflete-se, também, na precarização de infraestrutura do local, dado o abandono de órgãos públicos. Discute-se, ainda, como o atendimento no local é de baixa qualidade, porém sem ser discriminatório a seus frequentadores. Além disso, é analisado que, mesmo sendo considerado um local repleto de problemas, consumidores de baixa renda apresentam sentimentos positivos quanto ao Calçadão de Campo Grande. A relação desses consumidores com o calçadão no qual a pesquisa foi realizada pode ser explicada por acreditarem que seja um local mais em linha com suas realidades de escassez.
\end{abstract}

Palavras-chave: consumidor de baixa renda, polo comercial de rua, shopping center, significados de consumo. 


\section{ABSTRACT}

Despite representing a large pool of consumers in retail environments, there is a lack of studies in marketing in Brazil that discuss the relationship between low income consumers and these places, such as the calçadões. The present paper, therefore, analyzes the meanings associated by low income consumers to a calçadão, by using an interpretative perspective. For this, in depth interviews were conducted with 17 low income consumers in the Campo Grande Calçadão, in Rio de Janeiro. The data analysis discusses how the calçadão in question is seen as a popular place, especially because it offer prices considered low and gives the feeling of always being crowded. The precariousness of the infrastructure in the calçadão is also discussed, given the lack of attention of the government to such locale. Another line of discussion is regarding how the treatment of salesclerks is of low quality, but not discriminatory of the low income consumers that go there. It is also discussed how, even with so many problems, these consumers present strong positive feelings towards the Calçadão. This relationship of low income consumers with the calçadão in question can be explained by their belief that this place is more in line with their realities of scarceness.

Keywords: low income consumer, street retail, shopping mall, consumption meanings.

\section{Introdução}

O varejo no Brasil possui dois grandes centros de consumo. De um lado, existem os polos comerciais de rua (também conhecidos como calçadões), e, de outro, os shopping centers. Embora ambos ofereçam similaridades quanto à variedade de lojas, com as mesmas empresas presentes nos dois ambientes, há diferenças nos públicos que esses polos atraem. Enquanto que, historicamente, calçadões veem sendo mais frequentados por consumidores de baixa renda, shoppings se voltaram para satisfazer os desejos de consumidores de classes mais afluentes (PARENTE; MIOTTO; BARKI, 2007).

Uma explicação para essa relação entre polos comerciais de rua e consumidores de baixa renda está em sua localização. Segundo pesquisa do programa Polos do Rio, realizada em 18 dos 24 polos comerciais de rua cadastrados no Rio de Janeiro, a maior parte está em áreas onde predomina população de baixa renda (POLOS DO RIO, 2012). O fato de atraírem esses indivíduos torna os calçadões um importante local para manter uma loja, especialmente para empresas que focam em comercializar para consumidores de baixa renda (NOGAMI; VIEIRA; MEDEIROS, 2015).

Percebendo o potencial de compra de consumidores de baixa renda, shoppings também passaram a ser abertos em bairros mais populares, onde há menos lojas concorrentes e amplos espaços para grandes construções. Shoppings construídos em bairros próximos aos calçadões geralmente apresentam os mesmos estabelecimentos comerciais, porém com um diferencial: oferecem maior conforto ao consumidor, pois possuem um ambiente planejado, com uma variedade significativa de lojas, banheiros limpos, estacionamento, segurança e, em alguns casos, são adjacentes a estações de metrô (PARENTE; MIOTTO; BARKI, 2007). Porém, apesar dos diferenciais, as vendas de shopping centers em relação ao varejo nacional representaram $19 \%$ do volume total, valor esse considerado baixo visto o seu potencial como local para atrair grandes quantidades de consumidores e gerar elevadas vendas (ASSOCIAÇÃO BRASILEIRA DE SHOPPING CENTERS, 2016). Isso pode ser explicado, em parte, por consumidores de baixa renda ainda serem assíduos frequentadores de polos comerciais de rua. Nesses locais, encontram os mesmos produtos que aqueles oferecidos nos shoppings, porém em um ambiente com menos infraestrutura e, por vezes, mais cheio. Argumenta-se, portanto, que mesmo havendo shoppings próximos a tais calçadões, com diversos atrativos a mais que polos comerciais de rua, outros fatores devem ser considerados para explicar esse comportamento por parte desses consumidores. 
Um motivo para consumidores de baixa renda frequentarem assiduamente calçadões pode estar mais relacionado a aspectos simbólicos associados a tais locais do que a fatores funcionais, já que, em termos de funcionalidade, shopping centers, supostamente, teriam mais a oferecer (PARENTE; MIOTTO; BARKI, 2007). Diferentes estudos realizados no Brasil mostram os simbolismos que esses indivíduos associam a produtos e serviços, tais como eletroeletrônicos (PINTO, 2013), crédito financeiro (MATTOSO; ROCHA, 2008) e viagens em cruzeiros marítimos (ROCHA; ROCHA; ROCHA, 2016), indicando que o consumo lhes proporciona sentimentos de pertencimento à sociedade (CHAUVEL; MATTOS, 2008), possibilidades de diferenciação entre seus pares (CASTILHOS; ROSSI, 2009), aumento da autoestima (BACHA et al., 2008), entre outros benefícios. Considerando a linha de estudos de Consumer Culture Theory (CCT), que objetiva entender como a cultura influencia o consumo (GAIÃO et al, 2012), a partir da transferência de significados do mundo culturalmente constituído para bens de consumo (McCRACKEN, 2003), é possível conceber que ambientes varejistas também sejam locais repletos de simbolismos para indivíduos de baixa renda (SENNA; HEMAIS, 2017), que permitam ao consumidor encontrar felicidade e, assim, transformar suas vidas e o seu self (ARNOULD, 2005; MACLAREN; BROWN, 2005).

Apesar de representarem um grande e fiel público em ambientes varejistas, são poucos os estudos em marketing no Brasil que discutem a relação entre consumidores de baixa renda e tais locais, em especial os calçadões (PARENTE et al., 2012; TELLER, 2008). As pesquisas existentes tendem a analisar o fenômeno em questão a partir de uma visão positivista (PARENTE; MIOTTO; BARKI, 2007; SUTTER; PLUTARCO; PARENTE, 2012), deixando de considerar os possíveis aspectos simbólicos percebidos por esses consumidores a respeito de polos comerciais de rua. Diante dessa lacuna na literatura, o presente artigo busca analisar os significados associados por consumidores de baixa renda a um polo comercial de rua, no caso, o Calçadão de Campo Grande, por meio de uma visão interpretativista.

Após os comentários introdutórios, o restante do artigo está dividido em mais cinco tópicos. O segundo discute os significados do consumo para consumidores de baixa renda. $\mathrm{O}$ terceiro, por sua vez, versa sobre a relação entre esses consumidores com calçadões. Em seguida, no quarto tópico, é apresentada a metodologia adotada no estudo. No quinto, discutese a análise dos dados. Por fim, no sexto tópico, são feitas as considerações finais do estudo.

\section{Significados do consumo para consumidores de baixa renda}

O mercado de baixa renda no Brasil ganhou relevância após o advento do Plano Real, a partir do crescimento do seu poder de compra, resultante do controle inflacionário e o aumento real do salário mínimo. Empresas e o meio acadêmico, então, começaram a dar mais atenção ao segmento, realizando pesquisas que lhes permitissem mais bem conhecê-lo para, assim, poder comercializar adequadamente produtos a esse público (ROCHA; SILVA, 2009). Até então, pouco se sabia a respeito desses consumidores, considerados invisíveis dentro da sociedade (ROCHA, 2009).

Estudos sobre consumidores de baixa renda mostram que esses indivíduos possuem características singulares, que os diferem de consumidores de classes sociais mais afluentes (BARROS; ROCHA, 2009), e que se refletem continuamente nas suas escolhas de consumo (BOURDIEU, 2008). Mais do que os benefícios funcionais, o consumo de bens e serviços, antes inacessíveis a esses consumidores, possui importantes significados simbólicos (McCRACKEN, 2003), pois lhes dá um sentimento de inclusão na sociedade, já que por meio do consumo conseguem atender sua "necessidade social de relacionar-se com outras pessoas" (DOUGLAS; ISHERWOOD, 2009, p.26). A posse de tais bens representa a esses indivíduos não somente que estão em pé de igualdade com consumidores de mais alta renda, pois ambos estariam consumindo os mesmos produtos e serviços, mas também serve como diferenciador de seus pares de baixa renda (PEREZ; BAIRON, 2013), pois, afinal, existem os "pobres" e os 
"pobres pobres" (CASTILHOS; ROSSI, 2009). Esse processo de significação do consumo passa a afetar a identidade desses indivíduos, de forma que, quando perdem a possibilidade de consumir, sentem que perderam uma parte de si (MATTOSO; ROCHA, 2008), o que pode ser explicado pelo fato de produtos e serviços passarem a ser uma parte integrante do seu eu estendido, constituindo quem são (BELK, 1988).

$\mathrm{O}$ consumo de bens por parte de consumidores de baixa renda evidencia prazeres e frustrações com o ato de comprar. Esse paradoxo é fruto de uma dualidade de sentimentos: se, por um lado, sentem satisfação em suprir a família com bens desejados por todos, por outro, frustram-se por não ter a possibilidade de levar a quantidade e a qualidade que gostariam, devido a seus limitados rendimentos (MATOS; BONFANTI; METTE, 2014). Acabam, então, aprendendo a equilibrar os seus sentimentos, o que lhes dá uma extrema racionalidade quanto a seus gastos (BARKI; PARENTE, 2010).

O uso do consumo como uma afirmação social por parte de consumidores de baixa renda passa pela compra de bens que seus pares de mais alta renda também consomem. É comum que adquiram, portanto, produtos "de marca", pois preferem pagar mais caro por um bem, mas ter sentimentos de garantir que o investimento traz os benefícios prometidos (PRADO et al., 2014), o que acaba por resultar em uma relação única com determinadas marcas, quase como se essas fossem suas "melhores amigas" (FOURNIER, 1998). Por estarem consumindo produtos de marca, cujos preços, em geral, são mais elevados, esses indivíduos esperam ser tratados com mais respeito (HEMAIS; CASOTTI, 2014); quando tais produtos não atendem suas expectativas, sentem-se ressentidos, frustrados e, até, traídos (CHAUVEL; MATTOS, 2008).

Os simbolismos por trás do consumo também são percebidos em relação a polos varejistas (ARNOULD, 2005; O'GUINN; BELK, 1989). Frequentar esses espaços de consumo é uma atividade bastante apreciada por todas as faixas etárias do público de baixa renda (BACHA et al, 2008), até porque é uma das poucas formas de lazer ao qual esses consumidores possuem acesso (ROCHA; ROCHA, 2012). Os bons sentimentos quanto a estar e consumir em ambientes varejistas pode ser explicado porque, nesses locais, sentem-se como verdadeiros consumidores (SENNA; HEMAIS, 2017), e exigem, portanto, que o atendimento prestado a eles seja igual ao que é a consumidores de mais alta renda (CHAUVEL; SUAREZ, 2009). Entender isso é importante porque, mesmo que o preço seja um fator determinante para a decisão de compra por parte desses consumidores, o ambiente da loja e o atendimento recebido também possuem grande peso nesse processo (PARENTE; MIOTTO; BARKI, 2007).

À medida que mais conhecimento é gerado sobre os significados associados por consumidores de baixa renda ao consumo, percebe-se o quanto o acesso a produtos e serviços é importante em suas vidas, especialmente quando considerados os seus valores simbólicos. Isso justifica, portanto, entender a relação desse público com ambientes varejistas, em especial os calçadões, já que nesses polos comerciais esses consumidores ganham acesso a tais bens de consumo.

\section{Relação entre consumidores de baixa renda e calçadões}

No Brasil, polos comerciais de rua têm sido considerados importantes ambientes varejistas no que se refere a serem um local onde consumidores de baixa renda consomem (PARENTE; MIOTTO; BARKI, 2007). Quando surgiram, os calçadões não tinham um planejamento coerente, mas entendiam que era importante estar próximo a zonas para onde transportes públicos convergiam, de forma que o público pudesse acessá-los. Em geral, estão localizados não apenas nas regiões centrais de grandes cidades, mas também em zonas de periferia, onde há alta densidade geográfica de consumidores de baixa renda. A falta de coerência por trás do gerenciamento de tais locais ocorre porque não existe uma organização central para tomar decisões relativas àquele espaço, fazendo com que cada lojista tome decisões de maneira independente (TELLER, 2008). 
A incapacidade de polos comerciais de rua em controlar o composto de lojas cria dificuldades para se ajustarem ao público-alvo. Há lojas que, ao invés de agregarem positivamente ao espaço, afastam o consumidor, por serem ambientes desagradáveis e voltados a públicos distintos. Além disso, esses ambientes são, comumente, decadentes e confusos, devido à alta densidade e o calor, criando imagens negativas de si frente ao conforto dos ambientes planejados dos shoppings (TELLER, 2008).

Polos comerciais de rua ainda são responsáveis pela maior parte do volume de vendas do varejo no Brasil, pois há diversas empresas que investem nesse ambiente (PARENTE et al., 2012). Tais espaços onde ficam localizados são "mais democráticos", ou seja, permitem que empresas com menor capacidade de investimento abram lojas e ofereçam alternativas mais acessíveis a pessoas com rendas inferiores. Caracterizam-se, entretanto, por carecerem de diversos fatores relacionados à infraestrutura. Uma explicação para a situação mais precária de polos comerciais de rua é o abandono por parte de órgãos públicos, que resulta na falta de elementos atrativos à população (SUTTER; PLUTARCO; PARENTE, 2012).

A consequência da precarização da infraestrutura de polos comerciais de rua, no que diz respeito à atratividade para consumidores de baixa renda, leva esse público a buscarem alternativas de consumo nos shoppings próximos aos calçadões. Por entenderem que os polos de rua sofrem com falta de infraestrutura, shopping centers se aproveitam tal fato para se diferenciarem pela oferta de conforto. Assim, permitem a esses consumidores imaginarem que estão consumindo nas mesmas condições que seus pares de classes mais elevadas, algo que ainda é associado pelos primeiros a certo luxo (PARENTE et al., 2012).

As vantagens de consumidores de baixa renda em consumir em shoppings, entretanto, é envolta de problemas associados a discriminação de vendedores contra esse público, algo que, em calçadões, pouco se discute (AINSCOUGH; MOTLER, 2000). Isso, portanto, acaba se tornando um fator de valor para polos comerciais de rua, pois a relação entre consumidores de baixa renda e vendedores é de grande importância para determinar a sua decisão de compra (ANTONI; BASSO, 2016). Os calçadões, nesse sentido, acabam se tornando locais que atraem esses consumidores, por estarem mais em linha à realidade de escassez desse público, permitindo que não sejam lembrados de sua condição restrita de consumo (CHAUVEL; MATTOS, 2008), pois conseguem consumir adequadamente nesses polos de rua.

Mais do que o conforto, entretanto, o que pesa na decisão de consumidores de baixa renda em escolherem ir a um polo comercial de rua é a sua proximidade física. Essa avaliação ocorre não apenas por causa dos custos de deslocamento, mas, também, pela necessidade de reduzir o custo total de adquirir o produto desejado. Assim, em diversos casos, esses consumidores optam por se dirigir a polos comerciais de rua, por representarem somente uma viagem de ônibus, por exemplo, tornando menos onerosa a sua compra (BARKI; PARENTE, 2010).

A relação entre consumidores de baixa renda com calçadões ainda é um assunto pouco discutido pela literatura de marketing no Brasil (PARENTE et al., 2012). Dessa forma, o presente estudo espera contribuir para um maior entendimento sobre esse fenômeno a partir da pesquisa de campo aqui realizada.

\section{Metodologia}

Em razão de a presente pesquisa buscar compreender os significados associados por consumidores de baixa renda a polos comerciais de rua, já que há pouco conhecimento sobre o assunto abordado e o que existe é de natureza positivista (PARENTE et al., 2012), entende-se que um estudo interpretativo seja mais adequado para descrever o fenômeno em questão (CRESWELL, 2010). Diversos outros estudos no Brasil vem utilizando uma visão interpretativista para estudar o comportamento de consumidores de baixa renda (PINTO, 2013; ROCHA; ROCHA, 2012), reforçando a adequação da escolha feita aqui. 
Os participantes da pesquisa foram consumidores de baixa renda que frequentam o Calçadão de Campo Grande, um polo comercial de rua no município de Rio de Janeiro. O calçadão em questão está localizado em uma rua sem passagem para carros - o que facilita o trânsito de pedestres -, a menos de um quilômetro da rodoviária de Campo Grande e em frente a uma estação de trem. Logo, atrai milhares de consumidores por semana, com maior concentração nos finais de semana. Caracteriza-se por possuir aproximadamente 250 lojas comerciais, sendo algumas de grandes redes varejistas, tais como Ponto Frio, Casas Bahia, Lojas Americanas e Taco.

A coleta de dados foi realizada por meio de entrevistas em profundidade com consumidores de baixa renda que frequentavam o calçadão em questão. As entrevistas foram realizadas dentro de uma loja nesse polo de rua, em uma sala reservada, a qual os pesquisadores tinham acesso. A possibilidade de poder utilizar esse espaço foi, também, um dos motivos para o estudo ser feito no Calçadão de Campo Grande, já que em outros calçadões os pesquisadores não tinham acesso a uma sala onde as entrevistas poderiam ser conduzidas. Os consumidores eram abordados para participar da pesquisa, ao saírem da loja, e aqueles interessados eram levados até a sala. As entrevistas foram gravadas - com consentimento dos entrevistados - e posteriormente transcritas, para facilitar o processo de análise dos dados. Ao todo, foram gravados 687 minutos.

O presente estudo considerou que consumidores de baixa renda seriam aqueles das classes D e E, definidos a partir do critério de denominação de classes da Fundação Getúlio Vargas, que se baseia na classificação do IBGE em relação a salários mínimos. Ao todo, foram entrevistados 17 consumidores de baixa renda. Desses, seis homens e 11 mulheres. Do total de entrevistados, 12 se classificaram como pertencentes à classe $\mathrm{D}$ e cinco à classe $\mathrm{E}$. A média de idade dos entrevistados foi de 45 anos, sendo a pessoa mais nova com 20 anos e a mais idosa com 75 anos. Em relação a seu status social, 12 pessoas se declararam casadas, três solteiras, uma divorciada e uma viúva. Todas declararam serem moradoras de Campo Grande, no Rio de Janeiro, em locais próximos ao calçadão, o que reforça a ideia de que polos comercias de rua são frequentados por populações de baixa renda de regiões próximas, pois esses indivíduos têm dificuldades para se locomoverem a outros locais mais longínquos de consumo, por implicar em mais gastos com transporte (PARENTE; MIOTTO; BARKI, 2007).

Foi elaborado um roteiro de entrevistas, para guiar a coleta de dados, pré-testado com dois consumidores que se enquadravam no perfil desejado. Quando se trata de consumidores de baixa renda, o pré-teste de roteiros de entrevistas é fundamental, pois é comum que determinadas palavras encontradas frequentemente no vocabulário de consumidores de mais alta renda sejam de difícil entendimento para entrevistados do grupo em questão (CASOTTI; SUAREZ; DILEZA, 2009). Ao não serem detectadas dificuldades de entendimento das perguntas com os dois entrevistados, continuou-se com o mesmo roteiro para as demais entrevistas.

A análise dos dados ocorreu em duas etapas. Inicialmente, as transcrições foram analisadas utilizando o software Atlas/ti, versão 7, de maneira a codificar os dados coletados. Essa codificação se baseou no referencial teórico, mas também buscou extrair novos achados a partir dos relatos dos entrevistados (RUBIN; RUBIN, 2005). Essa codificação ajudou os autores a chegarem à saturação teórica dos dados, quando novos códigos deixaram de ser criados a cada nova entrevista analisada (GUEST; BUNCE; JOHNSTON, 2006).

Seguindo as diretrizes de Guest, Bunce e Johnston (2006), o processo de codificação foi iniciado com a leitura e atribuição de códigos da primeira entrevista realizada. A partir dessa, foram criados 38 códigos. O processo foi repetido para a segunda entrevista, obtendo-se 9 novos códigos (além dos 38 já criados inicialmente). À medida que novas rodadas de codificação eram realizadas, cada vez menos novos códigos eram criados por entrevistas, até que, a partir da $14^{\mathrm{a}}$ entrevista analisada a até a $17^{\mathrm{a}}$, novos códigos não foram mais criados. Segundo os autores, é 
nesse momento que se pode considerar que a pesquisa alcançou a saturação dos dados. Ao todo, foram criados 63 códigos a partir desse processo de codificação.

Após esse processo de codificação, foram gerados relatórios - extraídos do Atlas/ti - de cada um dos códigos, com trechos dos relatos dos entrevistados. A partir desses, foi possível começar a encontrar semelhanças e diferenças naquilo que os participantes da pesquisa reportavam sobre o fenômeno estudado. Esse procedimento de comparação dos relatos dos entrevistados é uma prática comum em pesquisas qualitativas de marketing (GUMMESSON, 2005; ANFARA. BROWN; MANGIONE, 2002), para que se possa chegar às categorias de análise da pesquisa. Essa etapa de análise dos dados permitiu que se chegasse a quatro categorias de análise do estudo, a saber: "As lojas do Calçadão são para o "povão": preços baixos e crowding" (formada por 17 códigos); "O Calçadão é para comprar, e só: a precariedade da infraestrutura" (20 códigos); "Atendimento ruim para todos, mas não discriminatório no Calçadão" (12 códigos); e “O carinho com o Calçadão" (14 códigos).

\section{Análise dos Dados}

O tópico a seguir discute a análise dos dados coletados na pesquisa de campo, sendo dividido em cinco subtópicos. No primeiro, discutem-se como as lojas do Calçadão são associadas a algo popular. No segundo, a infraestrutura do Calçadão é debatida. No terceiro, os vendedores e o atendimento do Calçadão são destacados. No quarto, a forte relação entre esses consumidores e o Calçadão é analisada. Por fim, no quinto subtópico, um resumo dos fatores vistos como positivos e negativos associados ao Calçadão de Campo Grande é apresentado, destacando como os achados da pesquisa se aproximam da literatura sobre o tema e as contribuições ainda pouco exploradas em marketing.

\subsection{As lojas do Calçadão são para o "povão": preços baixos e crowding}

Os entrevistados entendem que a variedade de estabelecimentos comerciais no Calçadão de Campo Grande é importante, mas não chegam a um consenso se esse ambiente é bem preparado nesse sentido. Grande parte dos consumidores associa a variedade com a quantidade de lojas existentes nesse ambiente, mesmo que não necessariamente essa relação exista. Embora acreditem que a variedade de estabelecimentos comerciais no Calçadão seja "boa", ressaltam o seu caráter mais popular: "Tem bastante loja, entendeu? Tem Marisa, tem C\&A, aqui no Calçadão. Tem bastante loja aqui. Só não tem as lojas, assim, mais de marcas. Aqui, eu acho assim, eu acho mais povão" (João).

Vale ressaltar que as marcas de lojas lembradas pelos entrevistados foram ou de empresas que têm como público-alvo o consumidor de baixa renda e ou de lojas âncora normalmente, de departamento ou magazines -, que ocupam grandes espaços no Calçadão. Em nenhuma das entrevistas foi relatada alguma marca específica de "boutique", ou seja, de uma loja especializada (as lojas "de marcas", apontadas por João). Essas lojas trabalham com uma ou poucas categorias específicas de produtos, para um público-alvo mais restrito, com ambiente mais moderno, cuidado na exposição das mercadorias, vendedores bem apresentados e preços superiores aos de outras lojas.

É bem possível que tais lojas especializadas não tenham sido lembradas pelos entrevistados porque não estão localizadas no Calçadão. À medida que cresce o número de empresas com foco em mercados de baixa renda e que buscam formas de alcançar esse público, algo que dificilmente ocorreria antes do advento do Plano Real e o crescimento do poder de consumo dessa população (ROCHA; SILVA, 2009), cada vez menos empresas cujo públicoalvo é de consumidores de mais alta renda se estabelecem em locais como o Calçadão. Essas "lojas de marca" acabam, então, preferindo se estabelecer em outros ambientes, tais como shopping centers, por atraírem o tipo de consumidores a quem desejam comercializar seus produtos e serviços (PARENTE; MIOTTO; BARKI, 2007). 
Esse entendimento de que no Calçadão há lojas "mais povão" faz os entrevistados imaginarem que, no polo comercial de rua, os produtos são mais baratos, levando-os a associarem o calçadão a algo "mais popular" e "menos elitista". Essa percepção sobre a variação de preço, entretanto, não ocorre com todas as lojas. Em algumas específicas, do tipo âncoras, tais como Casas Bahia ou Lojas Americanas, os entrevistados acreditam que o preço "é o mesmo em qualquer lugar", por serem grandes cadeias, que "tabelam" preços, pois todas as lojas da rede oferecem os mesmos produtos.

Os entrevistados parecem aceitar o fato de produtos custarem mais barato no Calçadão, mas assumem que não pesquisam preço, não tendo certeza, portanto, se essa realidade é verdadeira: "Se bem que brasileiro não tem esse negócio de consulta de preço. Você sabe que não rola isso" (Sandra). O presente achado mostra outra realidade à afirmação de que consumidores de baixa renda possuem extrema racionalidade quanto a seus gastos (BARKI; PARENTE, 2010), pois parece que, no polo de rua, os entrevistados não adotam a prática de comparação de preços, por acreditar que nesse local produtos e serviços são sempre mais baratos. A racionalidade para o consumo, portanto, é deixada de lado, para ser substituída por um sentimento de que as empresas no polo de rua reconhecem as realidades de escassez dos entrevistados (CHAUVEL; MATTOS, 2008), e que, por isso, não buscam se aproveitar dessa fragilidade financeira. Em consequência, o consumidor de baixa renda não precisa ser tão racional quanto a seus gastos quando vai ao Calçadão, pois sempre encontra nesse local: "os melhores preços do mercado" (Bruna).

O preço percebido como mais barato no Calçadão também gera, na visão dos entrevistados, maior densidade populacional dentro das lojas do local, cheias de consumidores buscando produtos "mais em conta". Por isso, as lojas do Calçadão são vistas como "amarrotadas", "muito cheias", causando desconforto em frequentá-las, algo que contribui para a imagem desses polos ser associada a decadência e confusão (TELLER, 2008). Consumidores tendem a ficar menos satisfeitos com a experiência de consumo à medida que aumenta a densidade humana no local onde consomem. A esse fenômeno, dá-se o nome de crowding (BRANDÃO; PARENTE; OLIVEIRA, 2012). A insatisfação é menor em ambientes onde existe uma infraestrutura mais adequada para atender grandes quantidades de pessoas e quando a ida do consumidor a um local de consumo está associada a lazer (QUEZADO; COSTA; PEÑALOZA, 2014).

Os entrevistados acreditam que o Calçadão é demasiadamente cheio por ser um local que "atrai muita gente", devido à variedade de produtos oferecidos a preços baixos. Como os próprios entrevistados são levados ao polo de rua pelo mesmo motivo, não recriminam seus pares por tornar o ambiente populoso demais. Na verdade, parecem aceitar que esse seja o custo a se pagar para poder comprar mais barato: "Só pobre aguenta isso aqui. A gente vem pelo preço, né?" (Sonia).

A percepção entre os entrevistados de que o Calçadão de Campo Grande é associado a preços baixos e lojas cheias, ou seja, a "povão", também passa pela ideia de que a infraestrutura desse polo comercial de rua é precária, conforme é discutido no item a seguir.

\subsection{O Calçadão é para comprar, e só: a precariedade da infraestrutura}

A infraestrutura do Calçadão de Campo Grande foi associada a precariedade e alvo de críticas dos entrevistados, fato esse que outros autores também já indicaram ser o item mais problemático de polos comerciais de rua (PARENTE; MIOTTO; BARKI, 2007). O abandono por parte de órgãos públicos (SUTTER; PLUTARCO; PARENTE, 2012) pode explicar essa percepção dos consumidores, já que faltam investimentos em elementos básicos para tornar esse ambiente varejista atrativo à população.

Essa visão parece afetar as associações feitas pelos entrevistados ao local, pois, no fundo, relacionam o Calçadão ao consumo de produtos e serviços, e só: “A gente só vem aqui 
pra comprar, e vai embora. Não tem motivo pra gente ficar mais" (Andrea). Os informantes deixam de lado, portanto, a ideia de que o Calçadão pode oferecer uma experiência de consumo memorável, de forma a fazer com que eles queiram ficar mais tempo no ambiente e, assim, consumirem mais do que apenas aquilo que lhes levou inicialmente ao local (PARENTE et al., 2012). Parece que, até por condições fisiológicas e de segurança, ficar no Calçadão mais do que o necessário, para "dar um passeio ou lanchar", por exemplo, é algo que dificilmente os entrevistados consideram como uma alternativa viável.

No caso específico do Calçadão de Campo Grande, os entrevistados mostraram insatisfação com a falta de banheiros públicos ("é horrível”, conta uma entrevistada) e opções de lazer, tais como cinemas ou área infantil; há "somente" lojas de roupas, sapatos, bares e lanchonetes. Existem também bancos no local, todavia, estão "sempre muito cheios", e a falta de segurança associada ao calçadão em questão se torna relevante quando se trata de sacar dinheiro.

A reclamação quanto à falta de banheiros públicos era acompanhada por explicações sobre como os entrevistados desenvolveram estratégias para quando precisam usar o serviço. Comumente, frequentam os poucos bares, lojas ou lanchonetes que possuem e permitem o uso do banheiro, mas desde que o consumidor consuma algum produto no recinto, o que gera insatisfação por terem que pagar por algo que entendem ser uma "obrigação do governo, dos lojistas". Alternativamente, os entrevistados contam como há um mercado próximo ao Calçadão, mas que também cobra para deixar pessoas utilizarem seus banheiros, o que, "no fim, dá na mesma”.

Por saberem que esse é um problema do Calçadão, os entrevistados parecem já saber de algum lugar que, em caso de necessidade urgente, podem utilizar o banheiro. Essa preocupação parece influenciar negativamente a decisão de alguns entrevistados em ir ao Calçadão, quando, por exemplo, estão na companhia de pessoas idosas. Nesses casos, relatam preferir ir a um shopping: "Chega a ser irônico ter que ir ao shopping só porque oferece banheiro!", conta Ana.

Outro ponto criticado pelos entrevistados é o estacionamento no Calçadão. Parente, Miotto e Barki (2007) indicam que esse serviço é importante para consumidores de baixa renda que possuem veículos por facilitar a ida ao local, tornado seu deslocamento mais agradável. Porém, quando os estacionamentos estão situados distantes do polo de rua, tornam-se mal vistos, pois perdem o apelo da comodidade. Esse parece ser o caso no calçadão em questão. Os entrevistados relatam "uma grande distância" entre os estacionamentos próximos ao Calçadão de Campo Grande e as lojas. Os entrevistados que possuem carro relatam que, por haver essa dificuldade, pensam primeiro nas opções de transporte público quando precisam ir ao local. Além da distância, também reclamam do preço cobrado para estacionar, sendo considerado caro.

A dificuldade de acessar as lojas a partir do estacionamento do Calçadão reforça, inclusive, o pensamento de alguns entrevistados de que, se estão de carro, o melhor é não ir ao polo de rua. O veículo de transporte desses entrevistados em particular não é próprio; precisam pedir um "favor" a um parente, e contar com a disponibilidade do dono do veículo para poderem utilizá-lo. Assim, quando optam pelo uso do carro, a ida a até algum ambiente varejista deixa de ser um simples ato de consumo de algo necessário e passa a ser um "programa", que envolve, frequentemente, mais de uma pessoa. Nesses casos, o destino de preferência deixa de ser o Calçadão e passa a ser um shopping, por esses oferecerem mais opções de lazer do que os polos de rua.

Outro ponto discutido pelos entrevistados é a falta de segurança do ambiente. Locais mais cheios, tais como polos comerciais de rua, oferecem mais possibilidades de indivíduos escusos se esconderem e furtar. Nesse ponto, os entrevistados são unânimes em apontar que não se sentem seguros no Calçadão: "Eu frequento há 12 anos esse calçadão e nunca fui 
assaltada. Mas, confesso que sou meio temerosa. Não sei se é o fluxo de gente, a agitação. A gente se sente meio insegura" (Ana).

Pelos relatos, é possível perceber que os entrevistados não sentem que o Calçadão é "uma zona de perigo", mas admitem que se preocupam com furtos e violência, até porque, em alguns casos, já sofreram desses maus no local. Relatam que dificilmente percebem a presença de autoridades policiais ou seguranças privados no Calçadão, tendo sentimentos de que "a única proteção é Deus". Todavia, não percebem o polo de rua como diferente de outros locais que frequentam. Relatos como "a gente não está seguro em lugar nenhum" e "falar de segurança no Rio de Janeiro é complicado" mostram que o Calçadão não oferece uma situação de risco adicional quando comparado a outros locais: “onde eu moro é 'quente' (no sentido de perigo). Aqui, no Calçadão, é até tranquilinho" (Carlos).

Não há intenções, entre os entrevistados, de deixar de frequentar o Calçadão por causa da falta de segurança. Ao invés, adaptam-se a ele: passam a carregar menos dinheiro em espécie e a manter bolsas e mochilas próximas ao corpo. Quando precisam de mais dinheiro, deslocamse até ao shopping mais próximo para sacá-lo. Também, evitam ir ao Calçadão em algumas datas de maior movimento, tais como Natal e Carnaval, por entenderem que, nessas épocas, é mais comum a presença de "trombadinhas" - por o local ficar mais cheio do que o normal -, que se aproveitam de consumidores "desatentos".

Mesmo que critiquem a falta de infraestrutura do Calçadão de Campo Grande, os entrevistados não enxergam isso como algo grave o suficiente para lhes fazer deixar de consumir no polo de rua. Alguns, ainda, dizem entender que nesse ambiente não existe localização ou público para serviços "mais sofisticados", tais como espaço de recreação infantil, cinema, fraldário ou bebedouro. Isso reforça a ideia de que o consumo no Calçadão é regido por uma lógica de racionalidade com base em preço do produto (BARKI; PARENTE, 2010): quanto menos infraestrutura, melhor, pois torna tudo mais barato, mesmo que isso signifique abdicar de serviços que possam tornar a experiência de compra mais agradável. Logo, o nível de exigência do consumidor quando frequenta o Calçadão é reduzido em relação a esses aspectos tidos como de segunda ordem.

Além da falta de infraestrutura, os entrevistados também indicaram outro fator envolto de problemas no Calçadão: o mau atendimento. $\mathrm{O}$ item a seguir analisa essa questão e discute como, mesmo sendo percebido como ruim, o atendimento tem um lado positivo, pois não é visto como discriminatório nesse polo comercial de rua.

\subsection{Atendimento ruim para todos, mas não discriminatório no Calçadão}

Em geral, os entrevistados se mostraram insatisfeitos com o atendimento recebido no Calçadão, referindo-se aos vendedores como "despreparados", com "falta de treinamento", não personalizando o atendimento, pois serviam todos de maneira igual: "Eu acredito que o atendimento daqui (Calçadão) é muito povão. E, então, o atendimento deixa um pouco a desejar... Aqui, como é muito povão... tem muito corre, corre, então, atende mal" (Geraldo). Isso é um fato preocupante porque, mesmo que o preço seja um fator determinante para a decisão de compra por parte desses consumidores, o atendimento recebido em estabelecimentos comerciais também é importante nesse processo (ANTONI; BASSO, 2016).

A baixa autoestima de consumidores de baixa renda (BARKI; PARENTE, 2010) parece se acentuar diante da má prestação de serviços do vendedor. Em parte, isso é explicado pelo sentimento de que o atendimento foi de baixa qualidade por causa da condição "de pobre" dos entrevistados. Por isso, desejam que os vendedores no Calçadão mudem para melhor. A partir do momento que esses consumidores passaram a consumir produtos de melhor qualidade, de marcas mais conhecidas, começaram a exigir que o atendimento dispensado a eles também fosse de melhor qualidade e, acima de tudo, respeitoso (HEMAIS; CASOTTI, 2014), assim 
como imaginam que é quando direcionado a consumidores de mais alta renda (CHAUVEL; SUAREZ, 2009).

É importante ressaltar, entretanto, que esses consumidores não acreditam que o atendimento no Calçadão seja ruim porque os vendedores são más pessoas. $\mathrm{Na}$ verdade, enxergam esses funcionários como sendo iguais a eles, ou seja, do segmento de baixa renda e, por isso, entendedores das dificuldades que esses consumidores passam. De certa forma, os entrevistados desculpam os vendedores por não lhes tratarem melhor, e atribuem o atendimento ruim ao fato de não haver orientação a esses funcionários sobre como lidar com clientes: "Aqui (no Calçadão), eles (os vendedores) não são treinados. Você pergunta uma coisa pra um, e ele fala uma coisa. Aí, pergunta pra outro, que fala outra coisa. Não é culpa deles, é falta de administração" (Mercedes).

Apesar do mau atendimento, os consumidores ressaltam que é incomum sentirem ou terem ouvido histórias de discriminação no calçadão, algo que reforça, segundo os entrevistados, a ideia de que os vendedores não são pessoas mal intencionadas. Nesse momento, diversos deles comparam suas experiências no polo de rua com as vivenciadas em shoppings, locais esses onde há maior incidência de atos discriminatórios direcionados a eles (AINSCOUGH; MOTLEY, 2000). Consumidores que já sofreram situações "desconfortáveis" como essas foram enfáticos em relatar a necessidade de se adequarem em termos de comportamento e vestuário ao ambiente do shopping para serem bem atendidos: "No shopping, existe a necessidade de você estar bem vestido e os vendedores agem como um "juiz" (Antonia), diferenciando o consumidor que merece o atendimento destinado às classes de mais alta renda a partir das roupas que estão vestindo.

A necessidade de mostrar que são merecedores de receber o atendimento dispensado a consumidores das classes de mais alta renda faz com que esses indivíduos de baixa renda se sintam obrigados a se vestirem melhor e a utilizarem acessórios que camuflem a sua identidade de pobre (CASTILHOS; ROSSI, 2009). Os informantes são críticos da própria aparência durante as entrevistas, mas justificam o fato de estarem vestidos de forma "simples" por estarem no Calçadão. Porém, se tivessem decidido ir a um shopping, acreditam que precisariam ter que se arrumar melhor: "Aqui, no Calçadão, você pode estar de bermudão, chinelo, shortinho", enquanto que, em um shopping, é preciso estar "arrumadinho", ao ponto de, até, usar "salto alto" ou "terno e gravata".

O consumidor de baixa renda, mais do que bem atendido, espera que a experiência no local de compra satisfaça o seu sentimento de aspiração social (PARENTE; BARKI; GEARGEOURA, 2008). Esse consumidor, que muitas vezes é complexado quanto ao seu status social e tem necessidade de afirmar que pode consumir em qualquer estabelecimento comercial, acaba, então, por sentir que não precisa se provar como um consumidor enquanto está no Calçadão, diferentemente do que ocorre quando está em shoppings:

Aqui no Calçadão, as pessoas, os vendedores, te tratam pelo que você é e no shopping te tratam pelo que você tem. Por exemplo, eu estou vestida normalmente aqui, e eu sou tratada normal. Lá, se eu fosse desse jeito que eu estou vestida, podia estar com dinheiro, mas teria certa diferença de tratamento. Eles olham a pessoa e tratam pela forma que a pessoa está vestida. Aqui não, é todo mundo igual. É todo mundo pé no chão (Flavia).

A visão dos entrevistados de que o atendimento ruim no Calçadão não resulta em discriminação, diferentemente do que ocorre em shoppings, ajuda a reforçar sua relação com esse polo comercial de rua e contribuir para que o local receba carinho por parte esses consumidores, conforme é discutido no item a seguir.

\subsection{O carinho com o Calçadão}


Em sua maioria, os entrevistados percebem de maneira positiva a imagem do Calçadão de Campo Grande e, de certa forma, até demonstram carinho quanto ao local. A maioria, além de elogiar o polo de rua e alegar que o recomenda para amigos e parentes, adota certa postura defensiva quanto a ele, chegando a encontrar justificativas para alguns dos aspectos negativos levantados anteriormente: "Eu não tenho nada contra o Calçadão, mesmo porque ele é bem útil para mim. Eu venho para cá, compro as coisas. Gosto do Calçadão. Não podemos falar muito mal, né? Não vamos malhar o que você utiliza?" (Laura).

Embora reconheçam os problemas do local, o Calçadão foi caracterizado pelos entrevistados como de "boa reputação", "familiar". Um entrevistado comentou que: "Quando vem o pessoal da Bahia, eu trago logo aqui, no Calçadão de Campo Grande" (Marcos). Justificam essa percepção indicando que, entre os calçadões que conhecem, o de Campo Grande é o que possui "pessoas mais trabalhadoras" e o que apresenta "menos violência". Por consumidores de baixa renda terem pouco acesso a atividades de lazer (ROCHA; ROCHA, 2012), é comum que famílias e pessoas de diferentes faixas de idade acabem frequentando espaços de consumo como forma de diversão (BACHA et al, 2008).

Os entrevistados têm consciência de que há problemas no Calçadão, mas isso não os leva a minimizar o valor do polo de rua: "A pessoa tem que ter um critério. Não pode pichar no geral. Você vai falar do banco, das lojas, da alimentação, vai falar do banheiro, cada qual em seu devido lugar. Porque, aí, você vai dar uma nota para cada coisa... Presta sim. O Calçadão é legal" (Geraldo). É possível que esses sentimentos de que não devem colocar o Calçadão em segundo plano possam ocorrer porque esses consumidores "dependem" desse ambiente varejista, em diversos casos, para realizar suas compras, já que o preço dos produtos encontrados no local é tido como mais barato. Mesmo aqueles entrevistados mais avessos ao Calçadão reconhecem que conseguem atender suas necessidades e desejos no local: "Eu tenho que me submeter a um lugar onde eu não me sinto bem, tipo o Calçadão de Campo Grande. Mas, por exemplo, um tênis pro meu filho foi mais em conta aqui do que no shopping" (Marcia).

Os entrevistados relatam que continuarão a frequentar o Calçadão, pois sentem uma forte ligação com o local. Alguns, inclusive, disseram que já o frequentavam "há muitos anos", de forma que já se sentiam familiarizados com o ambiente ("conheço tudo aqui. Sei onde está tudo") e acostumados com os problemas associados ao polo de rua: "nem percebo mais" (Bruna). A prolongada relação faz com que esses consumidores carreguem memórias de eventos positivos ocorridos nesse ambiente varejista, ajudando-os a formar afeto pelo local (PARENTE et al., 2012).

O Calçadão, nesse sentido, apresenta "defeitos", não é esteticamente atrativo e chega, até, a ser "desconfortável". Porém, tais características parecem refletir algo sobre as vidas dos entrevistados, que, segundo eles, estão longe de serem perfeitas. Talvez, por isso, esse polo comercial de rua seja um local onde esses consumidores sintam-se mais à vontade, aceitando quaisquer imperfeições, pois é um ambiente "mais real, mais eu" (Geraldo).

\subsection{Fatores de atração e de rejeição associados ao Calçadão: aproximação à literatura e novas contribuições}

A partir da análise apresentada, é possível chegar a um entendimento maior sobre fatores de atração e de rejeição percebidos pelos entrevistados no que diz respeito ao Calçadão de Campo Grande. O Quadro 1, a seguir, apresenta tais fatores.

Quadro 1 Fatores de atração e de rejeição associados ao Calçadão de Campo Grande

\begin{tabular}{|c|c|}
\hline Fatores de Atração ao Calçadão & Fatores de Rejeição ao Calçadão \\
\hline $\begin{array}{c}\text { Percepção de que preços de produtos são mais } \\
\text { baratos, em geral }\end{array}$ & $\begin{array}{c}\text { Infraestrutura inadequada, gerando } \\
\text { inconveniências e insegurança }\end{array}$ \\
\hline
\end{tabular}




\begin{tabular}{|c|c|}
\hline $\begin{array}{c}\text { Acesso ao local é fácil por meio de transporte } \\
\text { público }\end{array}$ & $\begin{array}{c}\text { Estacionamento em local distante de onde ficam as } \\
\text { lojas }\end{array}$ \\
\hline $\begin{array}{c}\text { Falta de necessidade de camuflar sua identidade, } \\
\text { pois vendedores não discriminam consumidores de } \\
\text { baixa renda }\end{array}$ & Atendimento dos vendedores é insatisfatório, ruim \\
\hline $\begin{array}{c}\text { Postura defensiva quanto ao Calçadão, por } \\
\text { representar algo próximo a consumidores de baixa } \\
\text { renda }\end{array}$ & $\begin{array}{c}\text { As lojas são demasiadamente cheias, acarretando } \\
\text { em percepção de crowding }\end{array}$ \\
\hline
\end{tabular}

Entre esses fatores de atração e de rejeição, há alguns que já foram mapeados pela literatura que discute a relação entre consumidores de baixa renda e polos comerciais de rua, enquanto que outros ainda são pouco explorados. A percepção de que preços no Calçadão de Campo Grande, por exemplo, são mais baratos do que em outros ambientes varejistas, tais como shopping centers, e que isso é um fator de atração para se dirigirem a este polo de rua, vai ao encontro de achados presentes no estudo de Parente, Miotto e Barki (2007). Por outro lado, a questão levantada pelos entrevistados de que a infraestrutura do calçadão analisado é inadequada, servindo de fator de rejeição ao ambiente, também já foi comentada por Sutter, Plutarco e Parente (2012) e Teller (2008).

A recorrente presença dessas questões em estudos sobre esse fenômeno parece indicar que essas são características marcantes do Calçadão. Isso pode ser uma sina ou uma benção para esse polo de rua, pois mudar tais características significaria não somente desfigurar algo que já faz parte das expectativas (altas ou baixas) de seus frequentadores, mas também de sua relação com o local. Embora a melhora na infraestrutura, por exemplo, seja necessária para atender a desejos mínimos daqueles que lá se encontram para consumir, uma melhora substancial desse ambiente pode também significar que passará a atrair mais outros consumidores que atualmente dificilmente são vistos nesse polo de rua, o que, em consequência, poderia desagradar consumidores de baixa renda que já são assíduos frequentadores do Calçadão.

Há, entretanto, achados do presente estudo que ainda não foram explorados suficientemente pela literatura especializada. Percebe-se, por exemplo, que consumidores de baixa renda sentem-se mais à vontade no Calçadão de Campo Grande, sem temer sofrerem discriminação por parte de vendedores que trabalham nas lojas que lá estão, ao contrário do que relatam quando frequentam shopping centers. Esse sentimento se mostra como um fator de atração para eles irem a esse polo de rua e parece estar bastante presente em suas vidas, pois discorreram a seu respeito sem que necessariamente tivessem sido estimulados a tanto. Esses indivíduos acreditam que, nesse ambiente varejista, existe mais respeito a quem eles são como consumidores (HEMAIS; CASOTTI, 2014), mesmo que possuam limitados recursos para realizar suas compras. A literatura de marketing que trata de discriminação em ambientes varejistas (SILVA JUNIOR; PARENTE, 2018) pouco aborda essa questão. Em geral, a posição socioeconômica do consumidor não é vista como causa prioritária para estimular a discriminação, sendo dada mais atenção a raça, gênero ou orientação sexual. Os entrevistados, todavia, indicam uma realidade diferente, que merece ser mais explorada, a fim de evitar novos comportamentos equivocados por parte de vendedores no futuro.

Outro ponto importante dos achados diz respeito à postura defensiva desse público quanto ao Calçadão. Mesmo que esse ambiente varejista seja envolto de problemas e críticas por parte dos próprios entrevistados, parece ser familiar a eles, onde se sentem à vontade, resultando na criação de laços afetivos com o local. A literatura de marketing que pesquisa a relação de consumidores de baixa renda com polos comerciais de rua tende a deixar de lado os sentimentos que esses indivíduos desenvolvem com tais ambientes varejistas, à medida que suas trajetórias pessoais passam a ser marcadas por diversos momentos que lá vivenciaram. Em geral, dá-se mais atenção a aspectos racionais dessa relação, tais como custos e benefícios de 
comprar no calçadão, esquecendo que, no fim, a escolha em ir e consumir nesse ambiente é permeada, sim, por decisões calculadas, mas, também, por sentimentos de bem-estar quanto ao local.

Uma explicação para o surgimento de achados no presente estudo que ainda foram pouco discutidos em marketing pode estar relacionada à abordagem interpretativista adotada. A partir dessa perspectiva epistemológica, é possível ir além das questões funcionais que pesquisas de cunho positivistas que também se dedicam a analisar o assunto aqui abordado pouco enxergam (PARENTE; MIOTTO; BARKI, 2007; SUTTER; PLUTARCO; PARENTE, 2012), para também incluir discussões relacionadas a cultura, simbologias e significados na análise do mesmo fenômeno (GAIÃO et al., 2012). Espera-se, portanto, que a pesquisa apresentada possa servir para estimular outros estudos a adotarem a perspectiva em questão, a fim de gerar mais conhecimento sobre a maneira como consumidores de baixa renda se relacionam com polos comerciais de rua, complementando, assim, os achados que estudos positivistas possam trazer.

\section{Considerações Finais}

O presente estudo teve como finalidade analisar os significados associados por consumidores de baixa renda a um polo comercial de rua, por meio de uma visão interpretativista. Para isso, realizaram-se entrevistas em profundidade com 17 consumidores de baixa renda que frequentam o Calçadão de Campo Grande. A partir da perspectiva interpretativista utilizada para analisar os dados, é possível chegar a algumas considerações finais.

Consumir no Calçadão não parece ser uma tarefa simples para consumidores de baixa renda. Há diversos fatores que servem para desincentivá-los a frequentarem o local, que vão desde a infraestrutura inadequada para lhes proporcionar uma experiência de compras mais prazerosa a até a falta de segurança. Mas, mesmo assim, esses indivíduos continuam a fazer desse polo comercial de rua um importante local de consumo. Adaptam-se aos fatores negativos associados ao ambiente a ponto de quase não mais notá-los. Essa adaptação, todavia, parece ser mais do que somente uma adaptação; pode ser entendida como um desejo desses consumidores em aceitar as falhas, pois os fatores positivos para consumir no Calçadão são mais importantes para eles.

As próprias falhas associadas ao Calçadão parecem, de alguma forma, não serem vistas de maneira totalmente negativa. Na verdade, parecem remeter os consumidores de baixa renda a quem eles são - indivíduos que, por não pertencerem à elite da sociedade, possuem vidas difíceis, imperfeitas, assim como o polo comercial de rua. Cria-se, então, um senso de pertencimento ao local, como se ele fosse daquela maneira por refletir quem eles próprios são. Devido às falhas, não se sentem constrangidos ou necessitados de mudar sua postura ou maneira de se vestir para consumir nesse ambiente varejista. Aceitam-no assim como é - inclusive, fazendo dele um espaço para levar amigos e familiares -, porque sempre foi um espaço deles. A infraestrutura ruim, a falta de segurança e o estacionamento longe das lojas todos podem ser reparados. Porém, o cultivo de laços duradouros, de anos, gravados na memória, está mais associado ao simbolismo por trás do que representa o Calçadão do que os aspectos tangíveis que oferece ou deixa de oferecer.

É claro que a existência de shopping centers que, agora, localizam-se em bairros onde consumidores de baixa renda residem e são adaptados para atendê-los torna esses indivíduos mais críticos quanto ao que lhes é oferecido no Calçadão. Passam a ter uma referência do que é um ambiente varejista que oferece conforto e segurança, mesmo que isso tenha um preço. Começam a entender que consumir é mais do que comprar; é uma experiência associada, em diversos casos, a lazer. Assim, podem agregar a família a esses momentos, trazendo bons sentimentos a diversas pessoas em torno de uma atividade em comum. Passam a desejar que 
calçadões também ofereçam mais do que o mínimo e a reclamar sobre sua falta. Parecem entender que tais benefícios são quase um direito, que os coloca em pé de igualdade com seus pares de mais alta renda. Afinal, se são consumidores, podem exigir serem bem tratados.

Dessa forma, a existência de shoppings próximos ao Calçadão de Campo Grande faz com que esses consumidores aprendam o que é consumir em um ambiente varejista. Isso significa passar a conhecer como um polo comercial de rua deve tratar seus clientes, seja na oferta de infraestrutura adequada ou atendimento profissional e cordial de vendedores, e a maneira como eles próprios devem se portar como consumidores.

Os resultados encontrados no presente estudo trazem informações úteis, tanto para empresas varejistas, quanto para o poder público e as associações comerciais locais. Para as primeiras, servem para mostrar os fatores positivos e negativos percebidos por consumidores de baixa renda associados a um polo comercial de rua e a forma como se relacionam com esse espaço comercial. A partir desse conhecimento, tais empresas podem buscar formas de se associarem mais ao Calçadão de Campo Grande, promovendo eventos e outras formas de entretenimento, aproveitando para si, portanto, as boas associações que esses indivíduos apresentam quanto ao ambiente varejista em questão.

Para o poder público e as associações comerciais locais, os resultados encontrados apontam para as preocupações dessa população quanto à falta de estrutura básica no Calçadão, o que pode significar, no futuro, uma maior migração desses indivíduos a frequentarem shopping centers, levando a um declínio cada vez maior desse polo comercial de rua. Esse cenário é grave, visto que calçadões têm importância econômica e social para municípios; seu declínio, portanto, é negativo para ambos a população que ali consome, quanto para os lojistas locais.

Entende-se que o estudo apresentado possui limitações, e que essas podem afetar seus resultados. Sugestões de futuras pesquisas, portanto, são feitas, para que tais questões possam ser analisadas. Em função de as entrevistas terem sido realizadas apenas no Calçadão de Campo Grande, tal fato pode ter influenciado os resultados sobre as associações feitas por consumidores de baixa renda acerca desse polo comercial de rua. Dessa forma, sugere-se que pesquisas futuras sejam realizadas com consumidores desse segmento em outros calçadões - e não somente no Rio de Janeiro -, para que seja possível analisar o quanto os resultados apresentados aqui são similares ou diferentes aos encontrados em outros polos comerciais de rua.

Apesar de o presente estudo não ter tido como foco discutir a relação de consumidores de baixa renda com shopping centers, comparações entre esses ambientes varejistas e o polo comercial de rua foram feitas pelos entrevistados. Sugere-se, então, que futuras pesquisas busquem estudar a relação entre esses consumidores com ambos esses polos comerciais, de forma a entender o que oferecem de positivo e negativo para esse público. Outro ponto que também foi pouco explorado na presente pesquisa, mas que surgiu nas falas dos entrevistados, foi a questão da discriminação vivida por eles quando frenquentam shoppings. Futuros estudos também poderiam aprofundar essa discussão, a fim de mais bem entender como esse fenômeno ocorre com consumidores de baixa renda em ambientes varejistas como este. 


\section{REFERÊNCIAS}

AINSCOUGH, T.; MOTLER, C. Will you help me please? The effects of race, gender and manner of dress on retail service. Marketing Letters, v.11, n.2, p.129-136, 2000

ANFARA, V.A.; BROWN, K.M.; MANGIONE, T.L. Qualitative analysis on stage: Making the research process more public. Educational Researcher, v.31, n.7, p.28-38, 2002.

ANTONI, V.; BASSO, K. Expectativas em relação ao varejo: um estudo com as consumidoras de confecções e calçados na base da pirâmide social. Revista Brasileira de Gestão de Negócios, v.18, n.2, p.593-608, 2016.

ARNOULD, E. Animating the big middle. Journal of Retailing, v.81, n.2, p.89-96, 2005.

ASSOCIAÇÃO BRASILEIRA DE SHOPPING CENTERS. Número do setor. Disponível em: http://www.portaldoshopping.com.br/monitoramento. Recuperado em 06, junho, 2016.

BACHA, M. L.; VIANNA, N.; SOUZA, S.; PEREZ, G. Lazer e classes populares: uma proposta de segmentação. Organizações \& Sociedade, v.15, n.44, p.81-99, 2008.

BARKI, E.; PARENTE, J. Consumer behavior of the base of the pyramid market in Brazil. Greenleaf Publishing, May, p.11-23, 2010.

BARROS, C.; ROCHA, E. Lógica de consumo em um grupo das camadas populares: uma visão antropológica de significados culturais. In: ROCHA, A.; SILVA, J. (Orgs.) Consumo na base da pirâmide: estudos brasileiros. Rio de Janeiro: Mauad X, 2009. 255p.

BELK, R. Possessions and the extended self. Journal of Consumer Research, vol.15, n.2, p.139-168, 1988.

BOURDIEU, P. A Distinção: crítica social do julgamento. Porto Alegre: Zouk, 2008.

BRANDÃO, M.M.; PARENTE, J.; OLIVEIRA, B.B. Percepção de crowding no varejo: uma investigação exploratória no mercado brasileiro. RAE-eletrônica, v.9, n.2, 2010.

CARSON, D.; GILMORE, A,; PERRY, C.; GRONHAUG, K. Qualitative Marketing Research. London: Sage Publications, 2005. 239p.

CASOTTI, L.; SUAREZ, M.; DILEZA, R. Consumo de alimentos nas famílias de baixa renda: compartilhando achados, experiências e aprendizados. In: ROCHA, A., SILVA, J. (orgs.) Consumo na base da pirâmide - estudos brasileiros. Rio de Janeiro: Mauad X, 2009.

CASTILHOS, R.; ROSSI, C.A. Subindo o morro: consumo, posição social e distinção entre famílias de classes populares. In: ROCHA, A.; SILVA, J. (Org) Consumo na base da pirâmide: estudos brasileiros. Rio de Janeiro: Mauad X, 2009. 255p.

CHAUVEL, M.A.; MATTOS, M. Consumidores de baixa renda: uma revisão dos achados de estudos feitos no Brasil. Cadernos Ebape, v.6, n.2, p.1-17, 2008.

CHAUVEL, M.A.; SUAREZ, M. Consumidores pobres e insatisfação pós-compra: "eles não têm respeito pela gente". In ROCHA, A.; SILVA, J. Consumo na base da pirâmide: estudos brasileiros, Rio de Janeiro: Mauad, 2009.

CRESWELL, J. Projeto de pesquisa: métodos qualitativo, quantitativo e misto. Porto alegre: Bookman, 2010.

DOUGLAS, M.; ISHERWOOD, B. O mundo dos bens: para uma antropologia do consumo. Rio de Janeiro: UFRJ, 2009.

FOURNIER, S. Consumers and their brands: developing relationship theory in consumer research. Journal of Consumer Research, vol.24, n.4, p.343-373, 1998.

GAIÃO, B. F. S.; SOUZA, I. L. S.; LEÃO, A. L. M. S. Consumer Culture Theory (CCT) já é uma escola de pensamento em Marketing? Revista de Administração de Empresas, v.52, n.3, p.330-344, 2012.

GUEST, G.; BUNCE, A.; JOHNSON, L. How many interviews are enough? : An experiment with data saturation and variability. Field Methods, v.18, n.1, p.59-82, 2006. 
GUMMESSON, E. Qualitative research in marketing: Road-map for a wilderness of complexityand unpredictability. European Journal of Marketing, v.39, n.3/4, p.309-327, 2005.

HEMAIS, M.; CASOTTI, L. Insatisfações projetadas de consumidores de baixa renda. Revista Pensamento Contemporâneo em Administração, v.8, n.4, p.65-84, 2014.

MACLAREN, P.; BROWN, S. The center cannot hold: consuming the utopian marketplace. Journal of Consumer Research, v.32, n.2, p.311-323, 2005.

MATOS, C.; BONFANTI, K.; METTE, F. Comportamento do consumidor endividado: um estudo exploratório com indivíduos de baixa renda. Gestão \& Sociedade, v.8, n.20, p.671687, 2014.

MATTOSO, C.; ROCHA, A. Building, losing, and reconstructing social identities : an investigation into the symbolic use of credit by poor consumers in Brazil. Latin America Business Review, v.9, p.227-256, 2008.

McCRACKEN, G. Cultura \& Consumo: novas abordagens ao caráter simbólico dos bens e das atividades de consumo. Rio de Janeiro: Mauad, 2003.

NOGAMI, V.; VIEIRA, F.; MEDEIROS, J. Construção de mercados: um estudo no mercado de notebooks para baixa renda. Gestão \& Regionalidade, v.31, n.93, p.59-75, 2015.

O'GUINN, T.; BELK, R. Heaven on earth: consumption at Heritage-Village, USA. Journal of Consumer Research, v.16, n.2, p.227-238, 1989.

PARENTE, J.; BARKI, E. Valor no varejo direcionado ao segmento de baixa renda. In: PARENTE, J.; LIMEIRA, T.; BARKI, E. (Orgs.). Varejo para a baixa renda. Porto Alegre: Bookman, 2008, 200p.

PARENTE, J.; BARKI, E.; GEARGEOURA, L. Varejo: luxo x baixa renda. GVexecutivo, v. 7, n. 1, p. 26-31, 2008.

PARENTE, J.; BRANDÃO, M.; MIOTTO, A.P.; PLUTARCO, F. Polos varejistas de rua ou shopping centers? comparando as preferências da baixa renda. BBR - Brazilian Business Review, Edição Especial BBR Conference, p.162-189, 2012.

PARENTE, J.; MIOTTO, A.; BARKI, E. Polos comerciais de rua. GVexecutivo, v. 6, n. 6, p. 49-54, 2007.

PEREZ, C.; BAIRON, S. Universos de sentido da população de baixa renda no Brasil: semânticas da estabilidade, da ascensão social e da mobilidade. MATRIZes, v.7, n.2, p.177$191,2013$.

PINTO, M. As experiências de consumo de eletrônicos de consumidores de baixa renda no Brasil. Revista Brasileira de Marketing, v.12, n.1, p.166-195, 2013.

POLOS DO RIO. Projeto censo dos polos 2011 - Relatório de pesquisa. Disponível em http://www.programapolosdorio.org.br/media/Censo_Polos\%20do\%20Rio_Relatorio\%20Co nsolidado_2011.pdf, acesso em 15 out. 2015.

PRADO, K.; BRITO, E.; SERRALVO, F.; TOLEDO, G. A preferência pela marca no processo de decisão de compra: um estudo exploratório no segmento de baixa renda. Organizações em Contexto, v.10, n.19, 357-382, 2014.

QUEZADO, I.; COSTA, R.B.L.; PEÑALOZA, V. Aglomeração e Valor de Compra em Centros de Consumo de Baixa Renda. Revista de Administração da UFSM, v. 7, n. 1, p. 4964, 2014.

ROCHA, A. R.; ROCHA, A. Consumidores da base da pirâmide e as restrições ao lazer. Revista Pensamento Contemporâneo em Administração, v. 6, n. 2, p. 1-13, 2012.

ROCHA, A. R.; ROCHA, A; ROCHA, E. Classifying and classified: An interpretive study of the consumption of cruises by the "new" Brazilian middle class. International Business Review, vol.25, n.3, p. 624-632, 2016. 
ROCHA, A.; SILVA, J. Consumo na base da pirâmide: um desafio para a pesquisa. In: ROCHA, A.; SILVA, J. (Org.) Consumo na base da pirâmide: estudos brasileiros. Rio de Janeiro: Mauad X, 2009. 255p.

ROCHA, E. Invisibilidade e revelação: camadas populares, cultura e práticas de consumo: apresentação. In: ROCHA, A.; SILVA, J. (Org.) Consumo na base da pirâmide: estudos brasileiros. Rio de Janeiro: Mauad X, 2009, 255p.

RUBIN, H.; RUBIN, I. Qualitative interviewing: the art of hearing data (2.ed). Thousand Oaks: Sage, 2005.

SENNA, S.; HEMAIS, M. Significados associados a shopping centers por consumidores da classe C. Revista de Administração da Unimep, vol.15, n.4, p.93-116, 2017.

SILVA JUNIOR, A.; PARENTE, J. Prejudice and racial discrimination in retail settings: perceptions and reactions of consumers in an emerging market. In: ROSSI, P.; KREY, N. (Eds.). Marketing Transformation: Marketing Practice in an Ever Changing World. AMSWMC 2017. Developments in Marketing Science: Proceedings of the Academy of Marketing Science. Cham: Springer, 2018.

SUTTER, M.; PLUTARCO, F.; PARENTE, J. Apresentação no ponto de vendas: um estudo exploratório no varejo de moda popular. Análise - Revista de Administração da PUCRS, v.23, n.1, p.5-18, 2012.

TELLER, C. Shopping streets versus shopping malls - determinants of agglomeration format attractiveness from the consumers' point of view. The International Review of Retail, Distribution and Consumer Research, v. 18, n. 4, p. 381-403, 2008. 